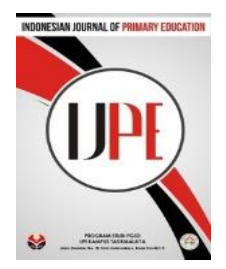

Vol. 2, No. 2 (2018) 76-81 ISSN: 2597-4866

Indonesian Journal of Primary Education

\title{
Desain Augmented Reality dalam Matakuliah Pendalaman Materi IPA
}

\author{
Rizki Hadiwijaya Zulkarnaen \\ Universitas Perjuangan Tasikmalaya \\ *Corresponding author: ridzkihadiwijaya@yahoo.com \\ Diterima 20 Agustus 2018; Direview 18 September 2018; Diterima 15 Oktober 2018 \\ Diterbitkan online 28 Desember 2018
}

\begin{abstract}
The development of science and technology has always been in line with the times. The dynamics of technological development provide a new culture for human life. A person's dependence on the use of technology in this case smartphone is one of the characteristics of a cultural shift. The results of the field study analysis show that the role of smartphones is closely related to life, but it is still minimal used for learning. This article explains the relevance of the role of smartphones in learning, especially science learning. Science is a field of science that emphasizes the process in which not only learn concrete concepts but also abstract. Difficulties in learning abstract concepts become one of the problems in understanding science learning. Augmented reality design is used as a solution for researchers in this matter. augmented reality is one smartphone application that can connect the real world with virtual, so that through the application of this program abstract concepts in science learning can be visualized so well that students are easier to understand.
\end{abstract}

Keywords: Smartphone, Augmented Reality, Science.

\begin{abstract}
Abstrak
Perkembangan ilmu pengetahuan dan teknologi senantiasa beiringan dengan perkembangan jaman. Dinamika perkembangan teknologi memberikan budaya baru bagi kehidupan manusia. Ketergantungan seseorang dalam penggunaan teknologi dalam hal ini smartphone menjadi salah satu ciri terjadinya pergeseran budaya. Hasil analisa studi lapangan menunjukkan bahwa peran smartphone erat kaitannya dengan kehidupan, namun demikian masih minim digunakan untuk pembelajaran. Artikel ini menjelaskan keterkaitan peran smartphone dalam pembelajaran khususnya pembalajaran IPA. IPA merupakan bidang ilmu yang menekankan pada proses yang didalamnya tidak hanya mempelajari konsep yang konkrit namun juga absktrak. Kesulitan dalam mempelajari konsep yang abstrak menjadi salah satu kedala dalam memahami pembelajaran IPA. Desain augmented reality dijadikan salah satu solusi peneliti dalam hal ini. augmented reality merupakan salah satu aplikasi smartphone yang dapat menghubungkan dunia nyata dengan maya, sehingga melalui aplikasi program ini konsep abstrak dalam pembelajaran IPA dapat divisualisasikan dengan baik dengan demikian mahasiswa lebih mudah untuk memahaminya.
\end{abstract}

Kata Kunci: Smartphone, Augmented Reality, IPA.

\section{PENDAHULUAN}

Ilmu pengetahuan dan teknologi semakin berkembang seiring dengan perkembangan jaman. Adanya teknologi memudahkan segala aktifitas yang dilakukan manusia. Aktifitas yang sulit, seperti halnya kasus mobilitas, komunikasi tanpa batas yang susah dijangkau pada waktu dulu, sekarang menjadi sangat mudah dengan adanya teknologi. Tidak terlepas dari hal tersebut, permasalahan dalam pembelajaran ilmu pengetahuan alam (IPA) juga dapat diatasi dengan adanya teknologi ini. Perkembangan teknologi dapat menginovasi suatu media pembelajaran yang dapat memberikan kemudahan dalam belajar IPA.

Ilmu pengetahuan alam (IPA) merupakan akumulasi dari content, process dan context (Kirkham dalam Wellington, 1989). Content menyangkut hal-hal yang berkaitan dengan fakta-fakta, definisi, konsep-konsep, prinsipprinsip, teori, model dan terminologi. Konsep 
yang dipelajari dalam IPA tidak semua dapat teramati dengan panca indra secara langsung (unobservable) sehingga siswa sekolah dasar yang pemikirannya masih dalam tahap konkrit tidak dapat memahami dengan baik. Seperti halnya ketika kita mencoba membelajarkan pendalaman materi IPA.

Pendalaman materi IPA merupakan salah satu mata kuliah wajib yang harus ditempuh oleh mahasiswa. dalam mata kuliah ini banyak muatan konsep yang bersifat unobeservable, diantaranya terkait sistem peredaran darah, sistem pencernaan, sistem pengangkutan mineral dan air pada tumbuhan serta sistem alam semesta. Mata kuliah ini mengarahkan mahasiswa agar memiliki kompetensi untuk dapat mengajarakan materi dari konsep pendalaman IPA terhadap anak sekolah dasar nantinya.

Keterbatasan panca indra kita dalam memahami konsep yang dipelajari memungkinkan untuk penggunaan media dalam pembelajaran. Salah satu media yang memungkinkan adalah penggunaan smartphone. Hasil analisa studi lapangan, smartphone merupakan alat yang tidak asing keberadaannya, baik bagi orangtua, guru, dosen, mahasiswa bahkan anak seusia SD juga sudah memiliki serta mampu untuk mengoperasikannya. Smartphone dalam hal ini digunakan untuk mengases program augmented reality yang dijadikan media dalam membelajarkan IPA.
Augmented reality merupakan inovasi program yang mampu menjembatani kondisi nyata (real) dengan virtual (Bronack, 2011; Klopfer \& Squire, 2008). Keunggulan dalam menggabungkan dunia real dan virtual, membuat program ini mampu memvisualisasikan suatu konsep yang abstrak dengan hubungan yang kompleks (Arvanitis et ala, 2007). Program ini dapat dirancang dengan memanfaatkan berbagai teknologi inovatif seperti halnya perngkat seluler (smartphone), komputer, dll (Wu et al, 2012).

Kemampuan program ini dalam memvisualisasikan suatu konsep yang abstrak menjadi problem solver terkait dengan keterbatasan panca indra kita dalam mengamati sesuatu. Dengan adanya program ini, konsep abstrak dalam pembelajaran pendalaman materi IPA dapat divisualisasikan dengan baik sehingga mahasiswa calon guru memahamkan siswa sekolah dasar sesuai dengan analisa perkembangan kognitifnya. Beberapa penelitian terdahulu tentang Augmented reality telah di lakukan di antaranya, augmented reality dapat memberikan pengalaman yang lebih mendalam bagi penggunanya karena teknologi tersebut menggabungkan dunia nyata dengan virtual (Klopfer \& Sheldon, 2010), dan augmented reality dapat meningkatkan interaksi serta keterlibatan penggunanya (Dede \& Mitchell, 2009). 
Berdasarkan pada pemaparan di atas, peneliti memfokuskan kajiannya pada desain augmented reality dalam pendalaman IPA.

\section{METODE PENELITIAN}

Metode penelitian yang digunakan dalam penelitian ini adalah jenis metode penelitian deskriptif kualitatif. Penelitian deskriptif merupakan suatu metode yang digunakan untuk menggambarkan atau menganalisis suatu hasil penelitian tetapi tidak digunakan untuk membuat kesimpulan yang lebih luas (Sugiyono, 205). Sederhannya, peneliti dalam hal ini menggunakan suatu cara untuk mencari fakta dengan interpretasi yang tepat (Whitney, 1960). Teknik yang digunakan peneliti meliputi studi lapangan terkait dengan permasalahan real yang terjadi di lapangan, serta studi literature guna mengatasi permasalahan yang muncul. Analisis data diperoleh melalui kegiatan wawancara, analisa dokumen, serta data pendukung lainnya yang berhubungan dengan penelitian. Pelaksanaan penlitian terjadi di salah satu perguruan tinggi swasta Tasikmalaya dengan sampel mahasiswa PGSD universitas tersebut.

\section{HASIL DAN PEMBAHASAN}

Pendalaman materi IPA merupakan salah satu mata kuliah wajib yang harus di ampu oleh mahasiswa PGSD salah satu perguruan tinggi swasta Tasikmalaya. Mata kuliah ini memuat terkait konten pendalaman serta bagaimana cara mengajarkan IPA, dengan demikian selain konten mahasiswa juga dituntut untuk mampu menguasai pedagogi dalam membelajarkan konten tersebut sehingga konsep yang diajarkan akan mudah di pahami oleh siswa ketika terjun ke sekolah dasar (SD).

Konten pendalaman materi IPA yang dipelajari dalam perkuliahan ini meliputi sistem pengangkutan zat cair dan mineral pada tumbuhan, sistem pencernaaan makanan pada manusia, sistem peredaran darah pada manusia, serta sistem alam semesta. Apa bila kita tinjau dari beberapa konten tersebut, konten yang diajarkan banyak bersifat unobservable artinya tidak dapat dilihat dan di amati secara langsung, seperti halnya bagaimana proses pencernaan dapat terjadi ataupun terkait dengan sirkulasi aliran darah yang terjadi pada manusia.

Sifat dari unobservable dari beberapa konsep dalam perkuliahan ini tidak terlalu menjadi masalah bagi mahasiswa untuk memahaminya, namun demikian hal tersebut menjadi suatu permasaalahan bagi mahasiswa calon guru itu ketika harus bisa mengajarkannya ke siswa di lapangan. Hal tersebut dikarenakan adanya perbedaan level kognitif dari siswa SD di lapangan. Siswa SD pada umumnya berada pada level kognitif konkrit, sehingga pembelajaran akan lebih bermakna apabila dibuat observable.

Keterbatasan pengamatan kita secara konkrit, menjadi salah satu permasalahan dalam penelitian ini. untuk memvisualisasikan suatu konsep yang unobservable menjadi observable maka perlu adanya penggunaan 
media. Desain media yang dirancangan dalam penelitian ini memanfaatkan program augmented reality. Program ini dapat diaplikasikan dalam smartphone. Berdasarkan analisa di lapangan, smartphone merupakan barang yang sudah menjadi umum bahkan menjadi salah satu kebutuhan, bahkan anak SD pun banyak yang memiliki serta mampu untuk mengaplikasikannya. Dengan demikian pengaplikasian program augmented reality dalam smartphone sangat memungkinkan untuk dikembangkan.

Secara sederhana augmented reality bisa didefinisikan sebagai lingkungan nyata yang ditambahkan obyek virtual. Penggabungan obyek nyata dan virtual ini dimungkinkan dengan teknologi display yang sesuai serta interaktivitas dimungkinkan melalui perangkat-perangkat input tertentu. Ronald T Azuma (1997) mendifinisikan augmented reality sebagai sistem yang menggabungkan dunia nyata dan virtual, interaktif dalam realtime dan register dalam 3D.

Sistem augmented reality bekerja berdasarkan deteksi citra dan citra yang digunakan adalah marker. Prinsip kerjanya, webcam yang telah dikalibrasi akan mendeteksi marker yang diberikan, kemudian setelah mengenali dan menandai pola marker, webcam akan melakukan perhitungan apakah marker sesuai dengan database yang dimiliki. Bila tidak, maka informasi marker tidak akan diolah, tetapi bila sesuai maka informasi marker akan digunakan untuk menampilkan objek 3D atau animasi yang telah dibuat sebelumnya.

Tahapan pembuatan media pembelajaran augmented reality adalah sebagai berikut:

1. Perancangan media merancang animasi yang akan di buat

2. Langkah awal terlebih dahulu dibuat objek yang akan ditampilkan. Secara umum objek yang dibuat adalah benda 3D, ataupun animasi yang dibuat dengan software perancangan objek seperti 3DMax, atau dengan Blender. Setelah objek jadi, maka objek tersebut akan disimpan ke dalam library.

3. Pembuatan marker. Marker adalah sebuah penanda yang memiliki pola khusus. Marker inilah yang nantinya akan dideteksi oleh webcam untuk menampilkan objek. Marker merupakan medium untuk memunculkan objek 3D

4. Menggabungkan 3 komponen yang telah di buat dengan unity 3D agar bias di tampilkan di kamera webcam (Viet Toan Phan 2010)

\section{Desain Augmented Reality (AR) dalam pendalaman materi IPA}

Pendalaman materi IPA memuat beberapa konten yang unobservable, dengan demikan kita tidak bisa mengamati secara langsung kecuali dengan menggunakan media. Augmented Reality merupakan salah satu desain program yang dikembangkan dimana konsep penggabungan dari kondisi real dengan virtual dapat memvisualisasikan hal yang unobservable. Beberapa konten yang 
tidak dapat teramati secara langsung dari pendalaman materi IPA diantaranya system pencernaan dan system peredaran darah manusia. Gambar 1 dan 2 merupakan ilustrasi dari pengembangan konsep melalui augmented reality.

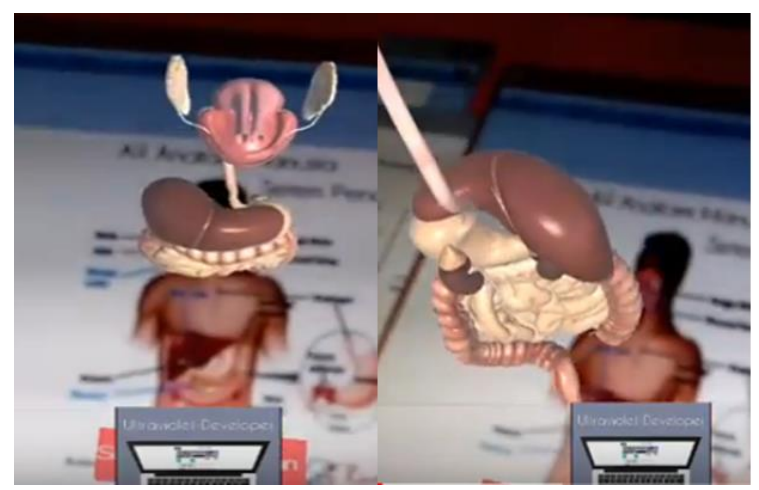

\section{Gambar 1}

Organ system pencernaan

Berdasarkan gambar 1, kita bisa mengamati dari gambaran dua dimensi yang tampak tidak terlalu nyata ketika menggunakan program augmented reality maka kondisi tersebut berupa menjadi tiga dimensi dengan tampilan lebih observable. Melalui program ini kita bisa menggerakan gambaran dari organ yang tercitrakan sehingga kita bisa meninjau dariberbagai sudut pandang terhadap organ tersebut layaknya dalam kondisi real. Adapun ilustrasi lainnya kita dapat melihatnya pada gambar 2 di bawah ini.

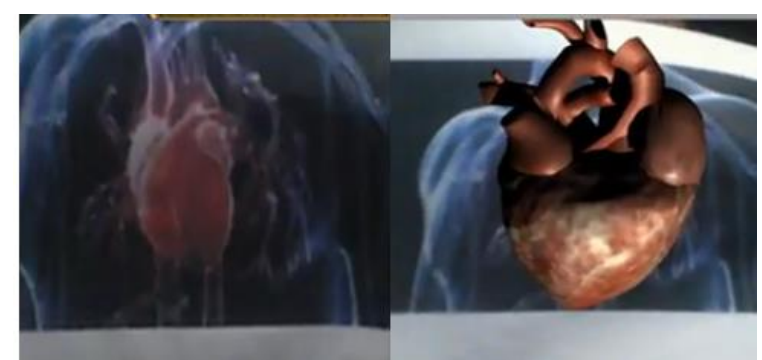

Gambar 2

Organ jantung dalam system peredaran darah dengan menggunakan augmented reality
Dari gambar 2 kita bisa melihat ilustrasi perbandingan hasil pencitraan dengan menggunakan augmented reality. Augmented reality memvisualisasikan konsep yang unobservable menjadi observable sehingga dapat teramati secara langsung. Dari gambar sebelah kiri tampak ilustrasi organ jantung dengan gambaran dua dimensi, sehingga kita sulit untuk mengetahui bagian dari organ tersebut, namun demikian setelah menggunakan augmented reality (terlihat pada gambar sebelah kanan) gambran terlihat nyata serta dat teramati dari berbagai sudut pandang.

\section{SIMPULAN}

Pendalaman materi IPA merupakan salah satu perkuliahan pendalaman bidang kajian IPA untuk mahasiswa PGSD, dimana tidak hanya konten tetapi juga harus mengetahui bagaimana cara mengajarkannya terhadap peserta didik yang memiliki tingkat pemikiran konkrit. Disatu sisi pendalaman materi IPA banyat memuat konten yang unobservable, dilain hal kita diharuskan bisa mengkonkirtkan konsep tersebut sehingga observable. Keterbatas dalam mengamati suatu konsep memungkinkan kita untuk menggunakan media, dalam hal ini augmented reality menjadi salah satu media yang diajukan. Augmented reality menghubungkan kondisi real dengan virtual sehingga mampu memvisualisasikan sutu konsep yang unobservable. Dengan demikian pemasalaham keterabatas pengamatan kita 
dalam dapat teratasi dengan penggunaan augmented reality.

\section{DAFTAR PUSTAKA}

Wellington. (1989). Skills And Processes In Science Education: a critical analysis

Bronack, S. C. (2011). The Role of Immersive Media in Online Education. Journal of Continuing Higher Education, VIX(II), 113-117.

http://dx.doi.org/10.1080/07377363.201 1.583186 .

Klopfer, E., \& Squire, K. (2008). Environmental Detectives: The Development Of An Augmented Reality Platform For Environmental Simulations. Educational Technology Research and Development, VVI(II), 203-228.

http://dx.doi.org/10.1007/s11423-0079037-6.

Arvanitis, T. N., Petrou, A., Knight, J. F., Savas, S., Sotiriou, S., Gargalakos, M., et al. (2007). Human Factors and Qualitative Pedagogical Evaluation of A Mobile Augmented Reality System for Science Education Used by Learners With Physical Disabilities. Personal and Ubiquitous Computing, XIII(III), 243-250.

http://dx.doi.org/10.1007/s00779-007-

0187-7.

Wu, H. K., Lee, S. W. Y., Chang, H. Y., \& Liang, J. C. (2013). Current status, opportunities and challenges of augmented reality in Education. Computers and Education, 62, 41-49.

Klopfer, E., \& Sheldon, J. (2010). Augmenting your own reality: student authoring of science-based augmented reality games. New Directions for Youth Development, 128, 85-94. http://dx.doi.org/10.1002/yd.378. augmented reality curricular unit. Journal of Computers in Mathematics and Science Teaching, 30(3),271-302.

Dede, C. (2009). Immersive interfaces for engagement and learning. Science, 323(5910), 66-69. http://dx.doi.org/10.1126/science.11673 11

Sugiyono. 2005. Metode Penelitian Administrasi. Bandung: Alfabeta

Whitney, F. 1960. The Element Of Research. New York :Prentice-Hall, Inc

Azuma, R. T. (1997). A survey of augmented reality. Presence-Teleoperators and Virtual Environments, VI(IV), 355-385.

Toan Phan, Viet, dkk (2010), Interior Design in Augmented Reality Environment International Journal of Computer Application Vol. V.

Mitchell, R. (2011). Alien contact!: exploring teacher implementation of an 